\title{
JARISCH-HERXHEIMER REACTION IN A PREGNANT WOMAN WITH GESTATIONAL SYPHILIS
}

\section{ORIGINAL ARTICLE}

Liborio-Neto, Adail Orrith ${ }^{1}$

Liborio-Neto, Adail Orrith. Jarisch-Herxheimer reaction in a pregnant woman with gestational syphilis. Revista Científica Multidisciplinar Núcleo do Conhecimento. Year 05, Ed. 07, Vol. 05, pp. 46-51. July 2020. ISSN:2448-0959, Access link in: https://www.nucleodoconhecimento.com.br/health/jarisch-herxheimer

\section{ABSTRACT}

The Jarisch-Herxheimer reaction is a feverish inflammatory reaction witch may occur after the treatment of patients for syphilis at all stages. Commonly begin between in the first 12 hours after treatment. In pregnant women the reaction may end up in prematurity and fetal death, especially when the fetus is infected. It's necessary to be aware of all the patient's complaints and take a look at to group them in a single medical diagnosis whenever possible. And it's principal that obstetricians always have JarischHerxheimer reaction as a medical diagnosis for febrile syndromes in pregnant women with syphilis.

Keywords: Jarisch-Herxheimer reaction, pregnancy, gestational syphilis, syphilis in pregnancy.

\section{INTRODUCTION}

The Jarisch-Herxheimer reaction (JHR) is It is a temporary and transient immunological event of characteristic onset usually seen in patients undergoing syphilis treatment. It's clinical manifestations are of non-specific symptoms like

\footnotetext{
${ }^{1}$ Federal University of Rio de Janeiro. Medical Intern, Faculty of Medicine, Macaé, Rio de Janeiro. 
myalgias, fever, chills and headaches, furthermore exacerbation of pre-existing cutaneous lesions. The complexity and still unclear interaction of its pathophysiological mechanisms continues to deceive the modern medicine, ever since it had been described in 1895 (BELUM et al., 2013).

The exact frequencies of JHR in the world according to age, sex, and other variables are not well documented because it's an unreported disease. Despite all of that, it's well known that there's a strong association with the syphilis and others spirochetal infection. But also several antibiotics like penicillins, tetracyclines, erythromycin, cephalosporins, levofloxacin, ciprofloxacin, clarithromycin, meropenem, and azithromycin have been reported in literature like a leading agent that can cause JHR. (DHAKA; SBAR, 2020.)

The standard signs and symptoms of the JHR began majority 2-8 hours after treatment dose, with fevers peaked at 6-12 hours' after the primary therapy and the whole event usually end by 16-24 hours after treatment. In pregnant women, the JHR can cause uterine contractions and decreased fetal activity beginning alongside with maternal fever. These events can be caused by increased and transitory prostaglandin F2 alpha and prostacyclin metabolites mediating the cardiovascular and uterine events in the post-treatment period. The JHR in pregnant women is analogous in frequency of event, characteristics and intensity of symptoms to that in nonpregnant women. However, the pregnant ones may have elevated uterine activity and transitory alterations in fetal wellbeing (KLEIN et al., 1990). In Brazil, the number of reported cases of syphilis in pregnant women has increased every year. Between 2008 and 2018, particularly from 2010 onwards, there was a progressive increase in the incidence of gestational syphilis and hence congenital syphilis (Brazil, 2017). This may have a major impact factor on the incidence of JHR in Brazil that is not being reported.

\section{CASE REPORT}

A 18-year-old Brazilian woman at her second pregnancy with 19 weeks of gestational age, came to the obstetric emergency department with erythematous, itchy, reddish, rounded, copper-red plaques, predominantly located on the lower limbs (Figure 1 and 
2). She had pain in her heels and calves and denied fever at the moment, but mentioned that had one fever episode at her home. The syphilis infection was detected using Venereal Disease Research Laboratory (VDRL) reagent. She reported that penicillin 7,200,000 IU was prescribed as 3 weekly doses of 2,400,000 IU for the treatment of gestational syphilis. She claimed that the symptoms started 24 hours after taking the last dose of Penicillin. Based on the clinical history and the symptoms, she was diagnosed with a Jarisch-Herxheimer reaction. The patient was medicated with antihistamine and corticosteroids. A cardiotocography was made showing normal patter and good fetus viability. After somes hours of observation at the obstetric yard she was discharged with orientations. The clinical symptoms disappeared after 24 hours. The obstetric exam showed that the fetus was health and was not infected.

Figure 1 and 2: Multiple erythematous reddish, rounded plaques on the lower limbs.
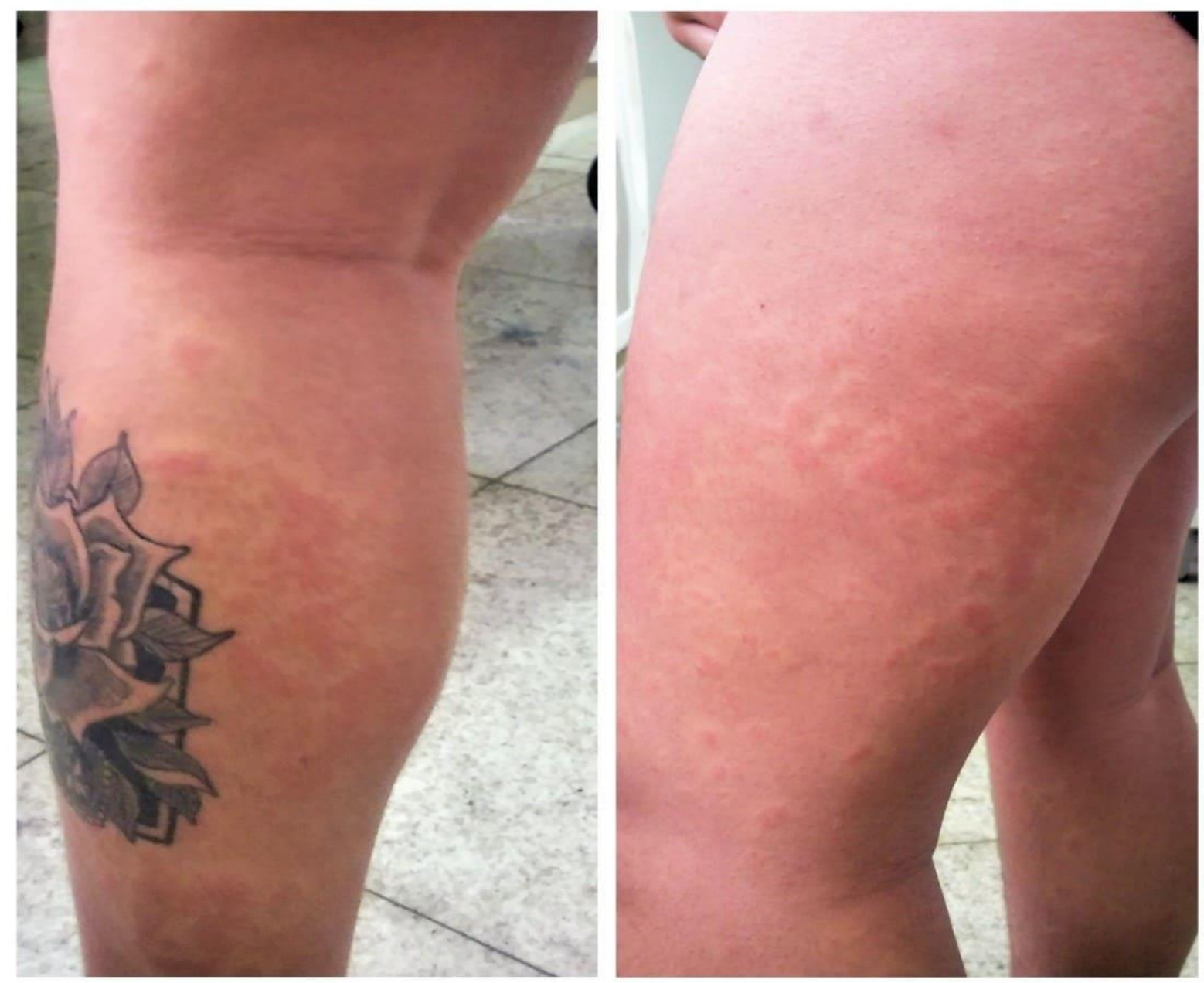


\section{DISCUSSION}

The Jarisch-Herxheimer (JHR) reaction is a febrile inflammatory reaction, usually starting within the first 12 hours after the first treatment dose (TSAI et al., 2014), but within the case, the reaction occurred $24 \mathrm{~h}$ after the third dose of the penicillin. It's most common clinical manifestations are the presence of fever, sweating, moderate to severe headache, signs of hypotension and worsening of pre-existing skin lesions (D'EÇA JÚNIOR; RODRIGUES; COSTA, 2018). Despite all the advances in the medical field, the exact mechanism of JHR is still unclear and thought to be multifactorial. It is hypothesized that the spirochete destruction after antitreponemal treatment could activate some cytokines cascades and release toxins and lipoproteins in the bloodstream. The penicillin treatment inhibits bacterial cell wall synthesis and this makes spirochetes more predisposed to phagocytosis. This immune process stimulates more cytokine release, including tumor necrosis factor and interleukins 6 and 8 and tumor necrosis factor-alpha, which result in the development of body aches, fevers, rashes, nausea and vomiting along with other symptoms (SEE; SCOTT; LEVIN, 2005; DHAKA; SBAR, 2020).

However, according to Barreira et al. (2015), during pregnancy, there is a suppression of responses related to cellular immunity (TH1) and a predominance of humoral and allergic responses (TH2). Characterizing a state of immunomodulation which could explain the late reaction within the last treatment dose. It is important for health professionals to understand and to know about JHR because it could be mistaken for penicillin hypersensitivity (GROSSI et al., 2011). Having that in mind, pregnancy complications of JHR include uterine contractions in most cases, decreased fetal movement in one third of the cases and fetal heart rate decelerations in half of the cases. The majority of those complications will be dismissed by 24 hours after the treatment however preterm birth and stillbirth can occur in severely affected pregnancies, despite normal anterior ultrasounds. (RAC; REVELL; EPPES, 2017.)

Myles et al.,1998 were the first ones that tried to estimate the incidence of the JHR in pregnant women undergoing treatment of syphilis and the incidence of changes in uterine activity or fetal heart rate. They reviewed retrospectively 50 charts of pregnant 
women diagnosed as needing treatment of syphilis and 31 available fetal heart rate records. The patients were admitted for the first dose of benzathine penicillin, and therefore the fetal vital sign was recorded continuously before and for twenty-four hours after injection. They found and incident of 20 cases of probable JHR estimating $40 \%$ of all theirs cases. However, despite the great incidence found, the study did not have a large number of participants and was limited to a small sample of pregnant. Thus could be these rates did not coincide with the reality to other obstetrics services worldwide.

Treatment is supportive with the employment of antipyretics and the use of intravenous fluid therapy. Corticosteroids could be proposed to decrease the intensity of the reaction, but evidence of efficacy is required, especially during the pregnancy (RAC; REVELL; EPPES, 2017). Fetal monitoring is imperative in these patients as recurrent variable decelerations are often seen. There are, however, various considerations to reduce the risk of reaction and improve outcomes in a patient, like antibiotic selection. The patient should be treated for manifested symptoms and be under observation until improvement of the case. The clinician and the obstetrician should forewarn the patient about the possibility of a reaction in cases of gestational syphilis (DHAKA; SBAR, 2020).

JHR must be an expected occurrence when treating any patient with syphilis or other treponemal diseases. The signs and symptoms of JHR should be anticipated and providers should properly educate the patient on this phenomenon. Most significantly, this case serves to remind practitioners that antibacterial therapy should be continued in these patients (SEE; SCOTT; LEVIN, 2005).

\section{CONCLUSION}

Jarisch-Herxheimer Reaction is often unrecognized and is underreported. Obstetricians should always have this entity as a differential diagnosis for febrile syndromes in pregnant women with syphilis mainly at this time of the syphilis epidemic in Brazil. 


\section{REFERENCES}

BARREIRA, Joana Filipa et al. Alterações imunológicas e da função tiroideia na gravidez e no período pós-parto. Arquivos de Medicina, v. 29, n. 2, p. 56-60, 2015.

BELUM, Geetanjali Reddy et al. The jarisch-herxheimer reaction: Revisited. Travel medicine and infectious disease, v. 11, n. 4, p. 231-237, 2013.

BRAZIL. Ministry of Health; Secretariat of Health Surveillance. Epidemiological $\begin{array}{llll}\text { Bulletin } & \text { Syphilis, } & 2017 . & \text { Available }\end{array}$ at:http://portalarquivos.saude.gov.br/images/pdf/2017/novembro/13/BE-2017038Boletim-Sifilis-11-2017-publicacao-.pdf.

D’EÇA JÚNIOR, Aurean; RODRIGUES, Lívia dos Santos; COSTA, Luciana Cavalcante. Jarisch-Herxheimer reaction in a patient with syphilis and human immunodeficiency virus infection. Revista da Sociedade Brasileira de Medicina Tropical, v. 51, n. 6, p. 877-878, 2018.

DHAKAL, Aayush; SBAR, Evelyn. Jarisch Herxheimer Reaction. StatPearls [Internet]. StatPearls Publishing, 2020.

GROSSI, Rinara et al. Reação de Jarisch-Herxheimer em gestante com sífilis: relato de caso. DST-J bras Doenças Sex Transm, v. 23, n. 3, p. 149-151, 2011.

KLEIN, Victor R. et al. The Jarisch-Herxheimer reaction complicating syphilotherapy in pregnancy. Obstetrics and gynecology, v. 75, n. 3 Pt 1, p. 375-380, 1990.

MYLES, Thomas D. et al. The Jarisch-Herxheimer reaction and fetal monitoring changes in pregnant women treated for syphilis. Obstetrics \& Gynecology, v. 92, n. 5, p. 859-864, 1998.

RAC, Martha WF; REVELL, Paula A.; EPPES, Catherine S. Syphilis during pregnancy: a preventable threat to maternal-fetal health. American journal of obstetrics and gynecology, v. 216, n. 4, p. 352-363, 2017. 
SEE, Sharon; SCOTT, Emilie K.; LEVIN, Marc W. Penicillin-Induced JarischHerxheimer Reaction. Annals of Pharmacotherapy, v. 39, n. 12, p. 2128-2130, 2005.

TSAI, Mao-Song et al. Jarisch-Herxheimer reaction among HIV-positive patients with early syphilis: azithromycin versus benzathine penicillin $G$ therapy. Journal of the International AIDS Society, v. 17, n. 1, p. 18993, 2014.

Submitted: June, 2020.

Approved: July, 2020. 